\title{
Characterization of Sicilian Olive Genotypes by Multivariate Analysis of Leaf and Fruit Chemical and Morphological Properties
}

\author{
Riccardo Lo Bianco ${ }^{1}$, Giuseppe Panno ${ }^{1}$ \& Giuseppe Avellone ${ }^{2}$ \\ ${ }^{1}$ Dipartimento Scienze Agrarie e Forestali, Viale delle Scienze 11, 90128 Palermo, Italy \\ ${ }^{2}$ Dipartimento Scienze e Tecnologie Biologiche Chimiche e Farmaceutiche, Via Archirafi 32, 90123 Palermo, \\ Italy \\ Correspondence: Riccardo Lo Bianco, Dipartimento Scienze Agrarie e Forestali, Viale delle Scienze 11, 90128 \\ Palermo, Italy. Tel: 39-091-2389-6097. E-mail: riccardo.lobianco@unipa.it
}

Received: August 28, 2013 Accepted: September 20, 2013 Online Published: October 15, 2013

doi:10.5539/jas.v5n11p229 URL: http://dx.doi.org/10.5539/jas.v5n11p229

\begin{abstract}
Leaf and fruit size and shape were measured and mannitol, glucose, sucrose and malic acid were quantified in leaf, bark and fruit of 25 Sicilian olive genotypes. Multivariate analysis was used to individuate groups with similar chemical composition and morphological traits suggesting potential for stress tolerance and/or oil yield and quality. Mannitol content varied greatly among genotypes and was the most abundant carbohydrate in leaf and bark, whereas glucose was the most abundant in fruit. Sucrose and malic acid were generally low indicating a marginal role in olive tissues. Mannitol and glucose were directly related in both leaf and fruit tissues. Genotypes also differed for carbohydrate partitioning among tissues, and multivariate analysis individuated a group of seven genotypes associated to leaf length:width, length:area, glucose, mannitol, and sucrose, which should stand for environmental stress tolerance. Multivariate analysis also individuated a group of six genotypes associated to malic acid, oleic acid, oleic:linoleic, and polyphenols, and therefore showing potential for production of high quality and stable olive oil. Overall, three of the 25 genotypes in trial seem to combine a good degree of abiotic stress tolerance with production of high quality and stable olive oil.
\end{abstract}

Keywords: glucose, leaf size, linear discriminant analysis, mannitol, principal component analysis, sucrose

\section{Introduction}

Olive (Olea europaea L.) is a species growing in Mediterranean and semi-arid regions where it commonly faces high temperatures and irradiation along with long periods of water deficit. In those regions, most of the olive oil is produced from trees typically grown in marginal areas (hilly sites and steep slopes) with little or no irrigation inputs (Favia \& Celano, 2005). Growth and yields of olive, as well as of most cultivated species, largely depend on the resistance to environmental stress (Moriana, Orgaz, Pastor, \& Fereres, 2003; Connor \& Fereres, 2005).

Some morphological traits, especially at the leaf level, can be indicative of stress resistance or tolerance. For example, leaf size, thickness and shape have been associated to leaf energy balance (Schulze, Robichaux, Grace, Rundel, \& Ehleringer, 1987) and hydraulic properties (Sack \& Holbrook, 2006), and they can ultimately reflect the species' level of adaptation to drought, as observed in Fraxinus (Abrams, Kubiske, \& Steiner, 1990).

During stress periods, olive is able to reduce water content and potential in leaves and roots, ceasing growth but maintaining some photosynthesis and carbohydrate accumulation (Xiloyannis, Dichio, Nuzzo, \& Celano, 1999; Dichio et al., 2003). This has been mainly attributed to the accumulation of compatible solutes (osmotic adjustment). In particular, mannitol (along with glucose and malic acid) seems to contribute to osmotic adjustment under water deficit (Xiloyannis et al., 1999) and salt stress (Gucci, Moing, Gravano, \& Gaudillére, 1998), and it increases in response to low temperatures in vitro (Rejšková, Patková, Stodůlková, \& Lipavská, 2007), whereas sorbitol plays a similar role in apple (Wang \& Stutte 1992), cherry (Ranney, Bassuk, \& Whitlow, 1991), and peach (Lo Bianco, Rieger, \& Sung, 2000).

Sorbitol and mannitol are polyols, or sugar alcohols, and are widely distributed in the plant kingdom (Bieleski, 1982). Specifically, mannitol comprises a significant portion of the soluble carbohydrate in species of Oleaceae, Apiaceae and Rubiaceae (Barker, 1955; Zimmermann \& Ziegler, 1975; Bieleski, 1982). It is synthesized in mature leaves after reduction of mannose-6-phosphate by a NADPH-dependent mannose-6-phosphate reductase 
followed by dephosphorilation by a mannitol-6-phosphate phosphatase. Once synthesized, mannitol may be accumulated in source tissues or transported to sink organs (Conde et al., 2007) where it is oxidized to mannose by a NAD-dependent mannitol dehydrogenase (Stoop, Williamson, \& Pharr, 1996; Noiraud, Maurousset, \& Lemoine, 2001).

It has also been suggested that mannitol and other polyols are strong water-structure formers acting as effective stabilizing/protecting agents at both molecular and whole-cell level (Galinski, 1993). Furthermore, polyols may function as scavengers of reactive oxygen species and represent a non-enzymatic mechanism to protect cells from oxidative stress (Smirnoff \& Cumbes, 1989). In transgenic plants exposed to salt or water stress, mannitol induces better survival and/or performance compared to wild types (Tarczynski, Jensen, \& Bohnert, 1993; Abebe, Guenzi, Martin, \& Cushman, 2003; Macaluso, Lo Bianco, \& Rieger, 2007), and this does not seem to be attributable to osmotic protection by mannitol (Karakas, Ozias-Akins, Stushnoff, Suefferheld, \& Rieger, 1997; Abebe et al., 2003) but rather to a more specific radical scavenging mechanisms (Shen, Jensen, \& Bohnert, 1997).

In addition to the above osmotic or anti-oxidative functions, various other advantages have been proposed for plants that produce polyols, like increased photosynthetic rates (similar to those of $\mathrm{C} 4$ species) and more efficient carbon and energy allocation (Pharr et al., 1995). Mannitol concentration in the olive fruit can also be indicative of the cultivar oil yield (Marsilio, Campestre, Lanza, \& De Angelis, 2001). This could be explained by the fact that more energy (NADH) is released during mannitol degradation compared to glucose; this additional energy is then available for oil biosynthesis via acetyl-CoA.

Olive oil is primarily composed of oleic acid and the ratio between oleic and linoleic acid may affect oil stability during storage and health properties after consumption (Rotondi et al., 2004). Carbohydrates generally function as precursors for lipid formation, but also for the biosynthesis of secondary compounds, like polyphenols and volatiles responsible for olive oil flavors and health properties (Conde, Delrot, \& Gerós, 2008). Carbohydrate composition and partitioning may therefore indirectly affect oil yield and quality.

Despite the amount of work classifying olive as a generally drought tolerant species, a relatively high number of cultivars and genotypes have been identified world-wide (Bartolini, Prevost, Messeri, \& Carignani, 1998) and even in Sicily (La Mantia, Lain, Caruso, \& Testolin, 2005), which may be different for their degree of stress tolerance. In particular, identification and use of more tolerant cultivars, also producing high quality oil, would allow for minimization of yield reductions due to environmental stress along with maximization of profits and health benefits. More detailed work is therefore needed to individuate morphological or biochemical traits that can efficiently discriminate olive genotypes according to their potential for stress tolerance and high quality oil production. In this study, we screened 25 Sicilian olive genotypes for carbohydrate content in various organs as well as leaf and fruit morphological traits, and used multivariate analysis to individuate groups of genotypes and factors that could discriminate them for stress tolerance and oil properties.

\section{Materials and Methods}

The trial was conducted on 20-year-old olive trees from a collection of local genotypes (see Table 1 for names and abbreviations) located near Scillato (37 50'14.94"N and $\left.13^{\circ} 56^{\prime} 47.47^{\prime \prime} \mathrm{E}\right)$, in Sicily. Trees were grown in an open field with conventional cultural cares and no irrigation. On 12 September 2006, four trees per genotype were selected and one bearing shoot $(0.5 \mathrm{~cm}$ in diameter $)$ per tree was sampled, transferred to the laboratory and stored at $-40^{\circ} \mathrm{C}$ for subsequent determination of glucose, sucrose, mannitol and malic acid.

In order to determine carbohydrate changes from source to sink tissues, mature leaves, internodal stem bark and fruit pulp at the pre-veraison stage were taken from each shoot, yielding a total of 420 samples for analysis at the gas chromatograph (GC).

Extraction was carried out using leaf blade portions, the bark of a 2-cm stem portion comprised between a leaf and a fruit, or longitudinal portions of the fruit pulp. Plant tissues were taken from the freezer, cut in small pieces with a razor blade, about $1 \mathrm{~g}$ was weighed, transferred into 1.5-ml eppendorf tubes and finely ground with a $\mathrm{V}$-shaped pestle in presence of liquid nitrogen. Ground tissues were extracted with $1 \mathrm{ml}$ of $80 \%$ (v:v) methanol solution containing $2.2 \mathrm{mg}$ of phenyl- $\beta$-glucopiranoside as an internal standard. Extraction was completed by vortexing for $1 \mathrm{~min}$ and centrifuging for $5 \mathrm{~min}$ at $3000 \mathrm{~g}$. The supernatant was transferred into clean eppendorf tubes and stored at $-40^{\circ} \mathrm{C}$ for subsequent $\mathrm{GC}$ analysis.

Preliminary tests were performed to optimize the derivatization method and develop a FAST run (7.5 min) on the GC. The primary aim of working with FAST GC was to reduce to about $1 / 5^{\text {th }}$ the time for each run, given the overwhelming number of samples. FAST GC essentially maintained the conventional analytical performance in 
terms of selectivity, sensitivity and resolution, while reducing costs of solvents, reagents and time of each analytical step. The method is robust and achieves good reproducibility in terms of separation and quantization of analytes.

Table 1. Abbreviations for names of the 25 Sicilian olive genotypes under trial

\begin{tabular}{lll}
\hline N. & Genotype local name & Abbreviation \\
\hline 1 & Biancolilla di Caltabellotta & BC \\
2 & Biancolilla napoletana & BN \\
3 & Biancolilla siracusana & BS \\
4 & Bottone di gallo & BG \\
5 & Brandofino & BR \\
6 & Calatina & CA \\
7 & Cavalieri & CV \\
8 & Cerasuola & CE \\
9 & Crastu & CR \\
10 & Erbano & ER \\
11 & Giarraffa & GF \\
12 & Lumiaro & LU \\
13 & Minuta & MN \\
14 & Moresca & MO \\
15 & Nerba & NE \\
16 & Nocellara del Belice & NOB \\
17 & Nocellara etnea & NOE \\
18 & Nocellara messinese & NOM \\
19 & Olivo di Mandanici & OM \\
20 & Passulunara & PA \\
21 & Piricuddara & PR \\
22 & Pizzo di corvo & PC \\
23 & Santagatese & SA \\
24 & Tonda iblea & TO \\
25 & Verdello & VE \\
\hline & & \\
\hline
\end{tabular}

A 50- $\mu 1$ aliquot of each extract was transferred into 2-ml GC vials and evaporated to dryness under nitrogen current. Derivatization was carried out by adding $75 \mu$ of BSTFA (N, O-bis (trimethylsilyl) trifluoroacetamide) and $15 \mu \mathrm{l}$ of piridine, followed by $15 \mathrm{~min}$ of sonication and $120 \mathrm{~min}$ at $75^{\circ} \mathrm{C}$. Carbohydrates were quantified with a Shimadzu 2010 GC (Columbia, MD, USA) using a Equity 5 fast column (15 m length, $0.1 \mathrm{~mm}$ inner diameter and $0.25 \mathrm{~m}$ film thickness; Supelco, Bellafonte, PA). Calibration curves were constructed with separate standards for glucose, sucrose, mannitol and malic acid using reagents from Sigma Aldrich (St. Louis, MO, USA).

On the same genotypes, leaf length, width and area, and fruit and pit height and diameter were recorded; fruit volume and flesh to pit ratio (flesh:pit) were calculated from size measurements (Tables 2 and 3). Indication of oil yield (high, medium or low as a percentage of fruit weight) and average data of oleic acid percentage, oleic to linoleic acid ratio (oleic:linoleic) and total polyphenols in oils from the same genotypes were taken from Caruso, Caltabellotta, \& Motisi (2007). Since information about the degree of drought tolerance was unavailable for all the genotypes under study, leaf length to area ratio (length:area, integrating information on leaf shape and size) was taken as an indicator of the level of adaptation to dry environments, and used to separate genotypes into 
three groups, potentially different for drought tolerance.

Carbohydrate data were analyzed by Analysis of Means; upper and lower decision limits were plotted and used to show differences of genotype means from grand mean. Correlation analysis was used to establish associations between carbohydrates in the same tissue or between tissues for each carbohydrate. Principal component analysis (PCA) was performed to investigate the relationship among leaf or fruit carbohydrates and morphological traits or chemical composition, and any possible cultivar grouping based on similar properties. Principal components were standardized to similar dimensions with the Biplot procedure, and cluster analysis with the k-means technique was performed on standardized component coordinates to individuate grouping of traits and genotypes. Linear discriminant analysis (LDA) was performed using leaf carbohydrates and traits to attempt classification of genotypes into the groups obtained with PCA, and ultimately to individuate the set of variables that would allow for discrimination of groups. LDA was also performed using group coding indicated by leaf length:area or oil yield levels. SYSTAT procedures (Systat Software Inc., Richmond, CA, USA) were used to perform the tests described above.

\section{Results and Discussion}

Mannitol content varied greatly among genotypes ranging from 153.8 to $487.5 \mathrm{mg} / \mathrm{g}$ of fresh weight (FW) in leaf, from 95.4 to $630 \mathrm{mg} / \mathrm{g} \mathrm{FW}$ in bark, and from 37.1 to $183.6 \mathrm{mg} / \mathrm{g} \mathrm{FW}$ in fruit. Also, greater average amounts of mannitol were found in leaf, where it is formed and it may accumulate in cytoplasm and vacuoles, and in bark, where it is translocated (Conde et al., 2007) and/or it may accumulate in parenchyma cells, compared to fruit flesh, where it is expected to be degraded and used as a source of carbon and reducing power (Figure 1). A decrease in mannitol content from leaf to fruit was common to all screened genotypes, but with various degrees of change. There was, in fact, no correlation among mannitol contents of various tissues, meaning that different genotypes may follow distinct strategies in the partitioning of mannitol among organs. Also, there was no significant difference in average mannitol content between leaf and bark, which would be in contrast with previous observations showing a totally symplastic pathway for mannitol phloem loading in olive (Flora \& Madore, 1993) and in favor of more recent findings supporting a dual (symplastic and apoplastic) loading system (Conde et al., 2008). In addition to this, significant amounts of mannitol may be stored in parenchyma cells of shoots and may have contributed to the high mannitol levels observed in our bark tissues. A previously reported function of mannitol as a reserve carbohydrate and osmoprotectant (Stoop et al., 1996), along with the relatively high variability of bark mannitol across genotypes seem to favor this scenario. On the contrary, the sharp mannitol decrease from bark to fruit may simply suggest high degradative activities in sink tissues. It is also consistent with low expression and activity of specific transporters and an energy-independent diffusion mechanism for mannitol unloading already reported in olive fruits when mannitol levels are high (Conde et al., 2007). 


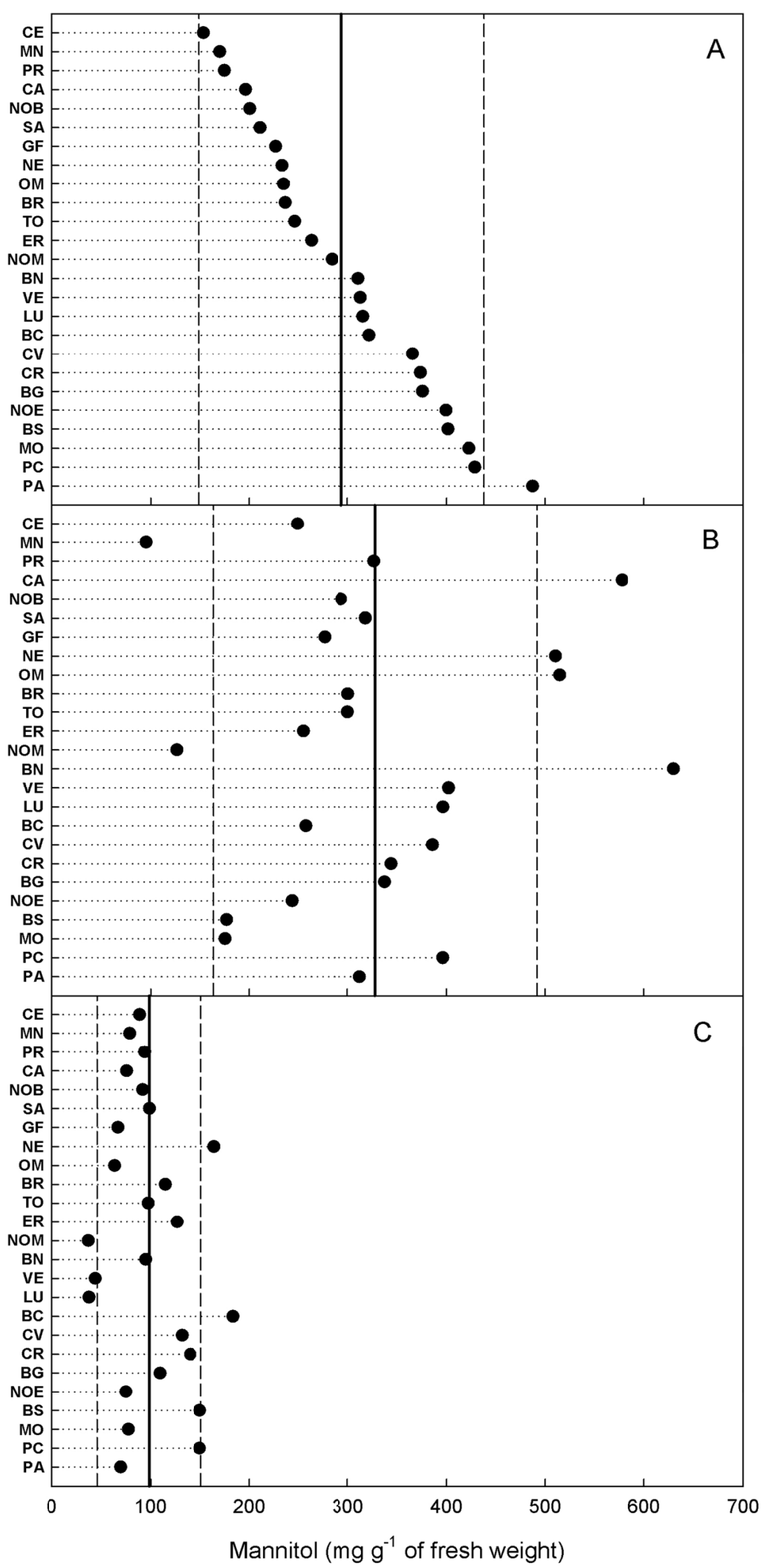

Figure 1. Mannitol content in leaf (A), bark (B) and fruit (C) tissues of 25 olive genotypes (data points are means of four replicates). Solid vertical lines indicate grand means of mannitol content in leaf $(\mathrm{N}=122)$, bark $(\mathrm{N}=119)$ and fruit $(\mathrm{N}=125)$. Dashed vertical lines indicate upper and lower decision limits from Analysis of Means $(\alpha=0.05)$ 


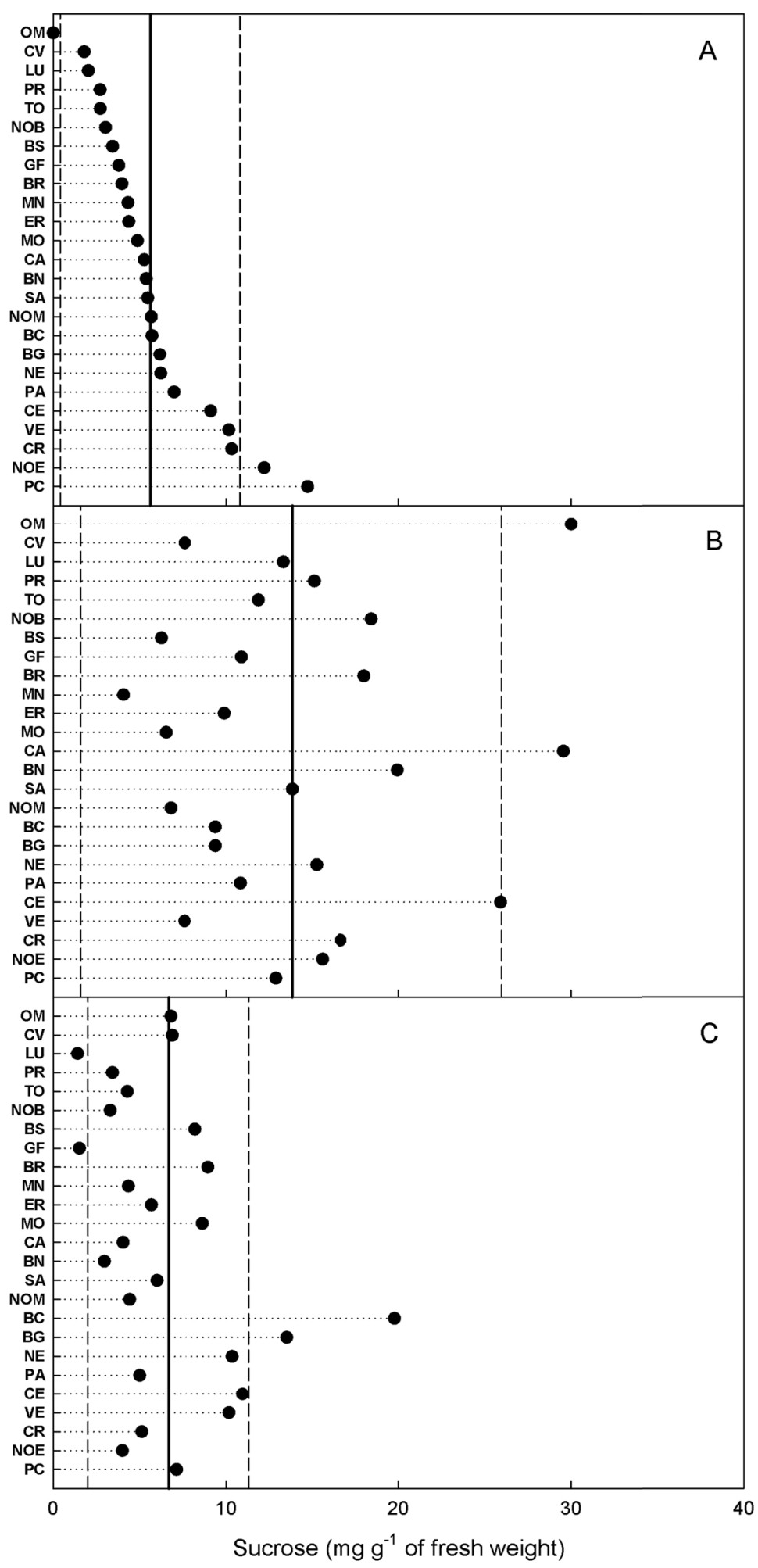

Figure 2. Sucrose content in leaf (A), bark (B) and fruit (C) tissues of 25 olive genotypes (data points are means of four replicates). Solid vertical lines indicate grand means of sucrose content in leaf $(\mathrm{N}=122)$, bark $(\mathrm{N}=119)$ and fruit $(\mathrm{N}=125)$. Dashed vertical lines indicate upper and lower decision limits from Analysis of Means $(\alpha=0.05)$ 


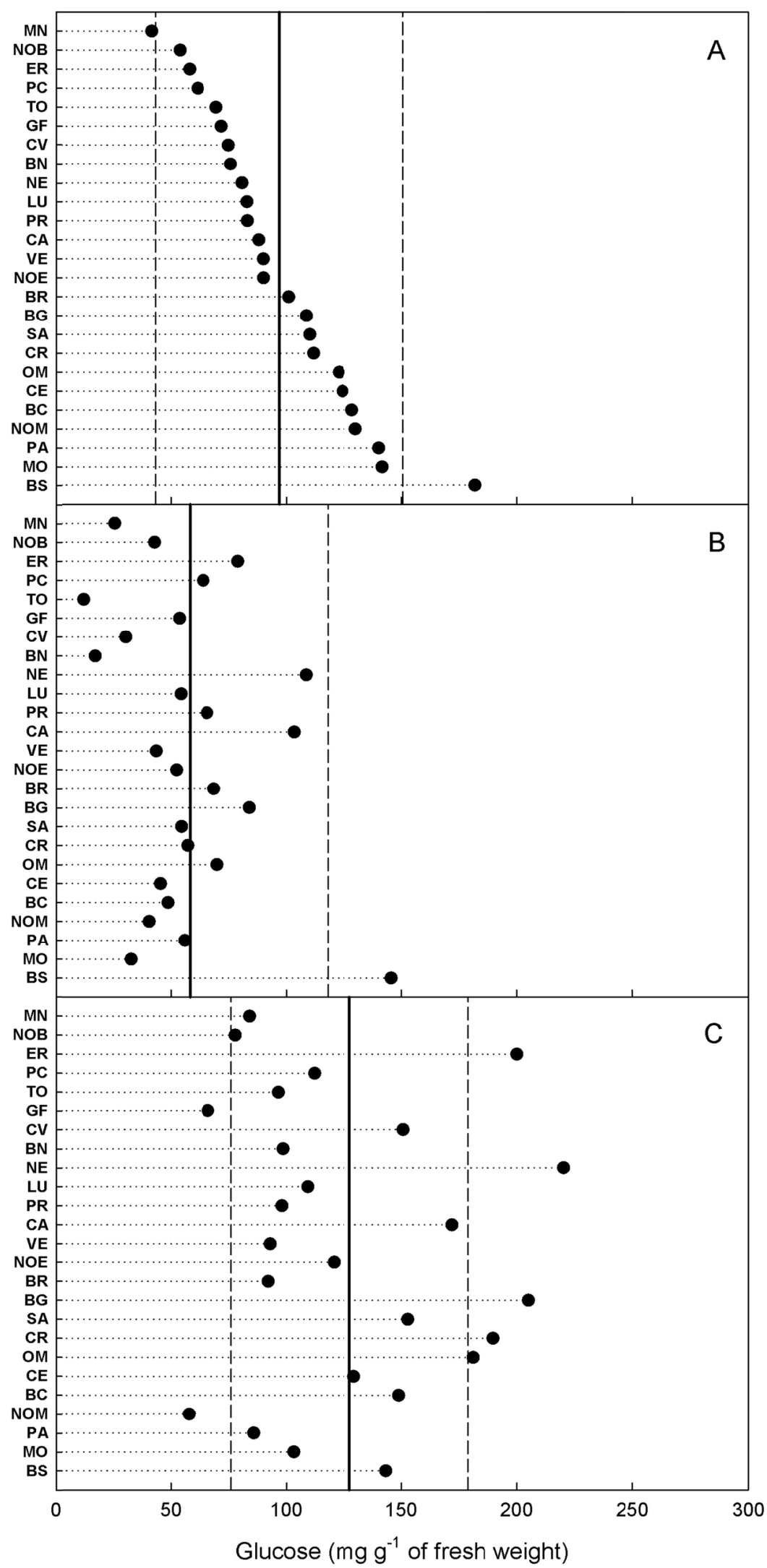

Figure 3. Glucose content in leaf (A), bark (B) and fruit (C) tissues of 25 olive genotypes (data points are means of four replicates). Solid vertical lines indicate grand means of glucose content in leaf $(\mathrm{N}=122)$, bark $(\mathrm{N}=119)$ and fruit $(\mathrm{N}=125)$. Dashed vertical lines indicate upper and lower decision limits from Analysis of Means $(\alpha=0.05)$ 
The high degree of variation along with accumulation in source tissues suggests that mannitol content may represent one key factor in screening for stress tolerance. Despite the large variation, in leaf, only PA had above average mannitol (Figure 1A). In bark, BN, CA, NE, and OM exhibited above average mannitol, whereas MN and NOM exhibited below average mannitol (Figure 1B). In fruit, BC and NE showed above average mannitol, whereas LU, NOM, and VE showed below average mannitol (Figure 1C).

Sucrose contents were generally much lower than mannitol contents in olive tissues. On an average basis, more sucrose was found in bark (13.8 mg/g FW) compared to leaf $(5.6 \mathrm{mg} / \mathrm{g} \mathrm{FW})$ and fruit $(6.7 \mathrm{mg} / \mathrm{g} \mathrm{FW})$ tissues (Figure 2). The relatively low amount of sucrose compared to mannitol, especially in leaf tissues, suggests that sucrose in olive trees is an initial product of photosynthesis mainly translocated from sources to sinks, and does not play a significant role as an osmolite or storage compound, at least in leaves. Low leaf sucrose was also reported by Tattini, Gucci, Romani, Baidi, \& Everard (1996) and Cataldi et al. (2000). In leaf, NOE and PC had above average sucrose, whereas OM had below average sucrose (Figure 2A). In bark, sucrose content exhibited high variability and only $\mathrm{OM}$ and $\mathrm{CA}$ showed above average levels, whereas the remaining genotypes were comprised within decision limits (Figure 2B). In fruit, BC and BG showed above average sucrose, whereas LU and GF showed below average sucrose (Figure 2C).

Glucose was also abundant in olive tissues, especially in fruit $(127.5 \mathrm{mg} / \mathrm{g} \mathrm{FW})$, where it derives from the active degradation of transport carbohydrates. In those tissues, glucose may represent a measure of metabolic rates and a temporary osmolite favoring cell turgor and growth. Glucose was also detected in relatively large quantities $(97.0 \mathrm{mg} / \mathrm{g} \mathrm{FW}$, about $1 / 3$ the amount of mannitol) in leaves, where it should contribute to osmotic adjustment (Gucci et al., 1998; Xiloyannis et al., 1999). The relatively low amounts detected in bark (58.3 mg/g FW) should be primarily due to its presence in tissues other than the phloem (i.e., cambial and parenchyma cells) as glucose is generally not stable enough to be transported. In both leaf and bark, BS had above average glucose, whereas in leaf only, MN showed below average glucose (Figure 3A and B). In fruit, BG, CR, ER, NE, and OM showed above average glucose, whereas GF and NOM showed below average glucose (Figure 3C)

Malic acid contents were generally low, ranging from $2.2 \mathrm{mg} / \mathrm{g} \mathrm{FW}$ in leaf to $18.0 \mathrm{mg} / \mathrm{g} \mathrm{FW}$ in fruit, with intermediate values of $5.0 \mathrm{mg} / \mathrm{g}$ FW in bark. In leaf, malic acid was not detected in six genotypes, while BG, BN, $\mathrm{CE}$, and CV exhibited above average levels (Figure 4A). In bark, only TO showed above-average malic acid, whereas the remaining genotypes were comprised within decision limits (Figure 4B). In fruit, BC, CA, CV, and SA showed above average malic acid, whereas BN, LU, and PR showed below average levels (Figure 4C). Despite the significant increase of malic acid reported in olive under water deficit (Xiloyannis et al., 1999) and salt stress (Gucci et al., 1998), the low levels observed in this study, along with relatively little variation among genotypes in leaves, suggest a marginal osmotic role of malic acid and a minor factor in screening for stress tolerance. 


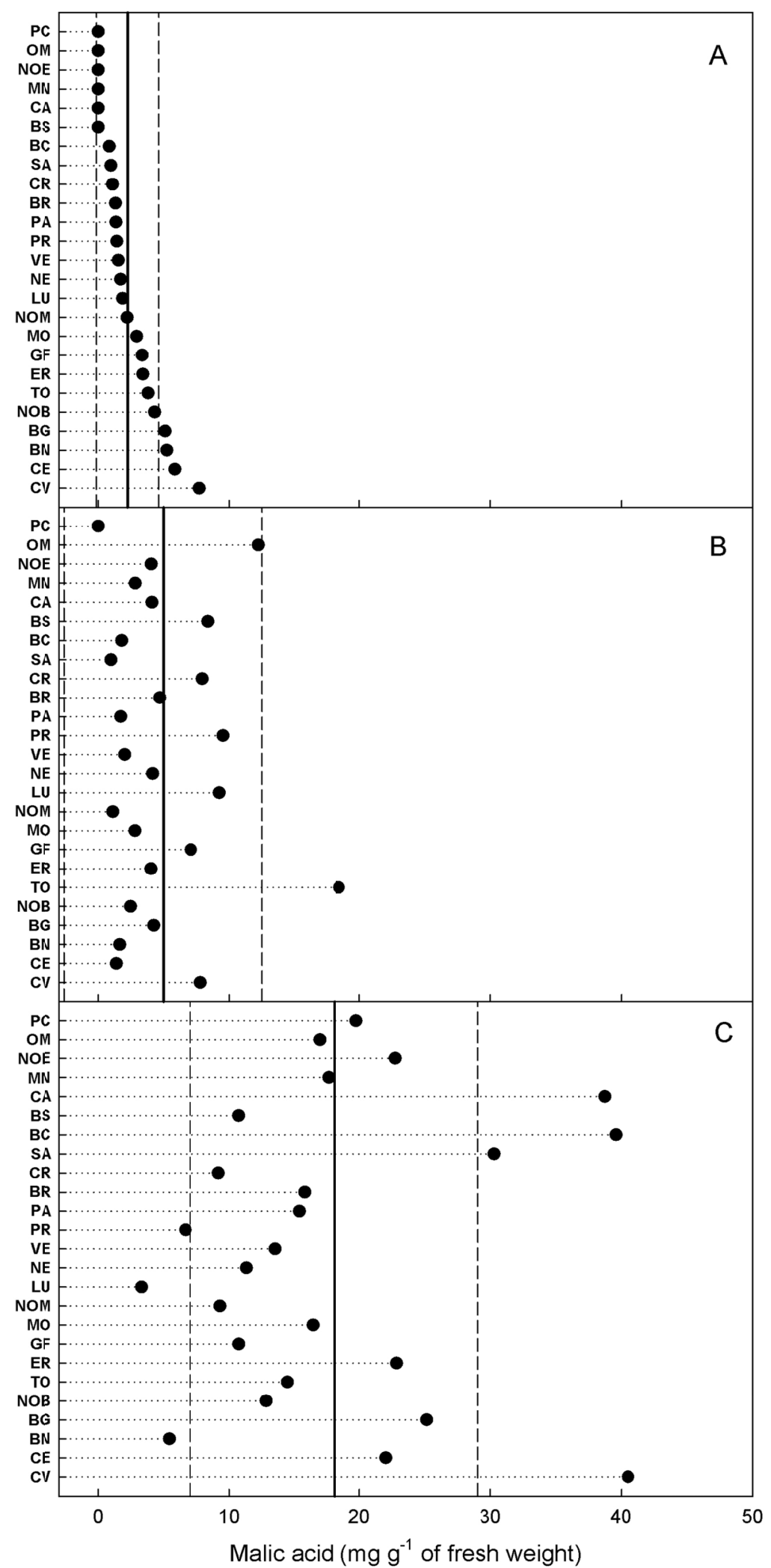

Figure 4. Malic acid content in leaf (A), bark (B) and fruit (C) tissues of 25 olive genotypes (data points are means of four replicates). Solid vertical lines indicate grand means of malic acid content in leaf $(\mathrm{N}=122)$, bark $(\mathrm{N}=119)$ and fruit $(\mathrm{N}=125)$. Dashed vertical lines indicate upper and lower decision limits from Analysis of Means $(\alpha=0.05)$ 
In leaf tissues, simple correlation analysis showed a positive relationship between mannitol and glucose $(\mathrm{r}=0.41$, $\mathrm{P}=0.042)$. In bark tissues, sucrose was directly related to mannitol $(\mathrm{r}=0.62, \mathrm{P}<0.001)$. In fruit tissues, sucrose was directly associated with malic acid $(r=0.47, \mathrm{P}=0.018)$, glucose $(\mathrm{r}=0.40, \mathrm{P}=0.045)$ and mannitol $(\mathrm{r}=0.55$, $\mathrm{P}=0.005)$; also mannitol and glucose were directly related $(\mathrm{r}=0.54, \mathrm{P}=0.006)$. Neither mannitol nor sucrose of bark tissues was associated with mannitol or sucrose in leaf or fruit tissues, suggesting that apoplastic steps and specific carriers may be involved in the loading and unloading of the two carbohydrates.

When leaf size, shape, carbohydrate levels, and genotypes were considered together, PCA showed that about $73 \%$ of the variability observed was explained by the first three components (Table 4). PC1, PC2, and PC3 accounted for 35,21 , and $17 \%$ of the total variability, respectively. Although the number of principal components considered does not allow for an easy interpretation of associations, further analysis with perceptual mapping procedures (biplot) and clustering produced some interesting results. In particular, the analysis revealed some expected associations like the one between leaf length:width and length:area, some associations already revealed by simple correlation analysis, like the one between mannitol and glucose, and some other interesting relationships, like the association between leaf shape or size parameters and sugars (glucose, mannitol and sucrose) (Table 5). But most importantly, cluster analysis on standardized component scores allowed for the individuation of three main groups associating specific leaf parameters with certain genotypes. In particular, cluster analysis indicated that BC, BS, MO, NOE, PA, PC, and VE form one group along with leaf length:width and length:area, glucose, mannitol, and sucrose; BN, BR, CA, CR, CV, GF, NE, NOM, and TO form a second group along with malic acid; BG, CE, ER, LU, MN, NOB, OM, PR, and SA form a third group along with leaf area (Table 5). It is interesting to notice that the grouping obtained in this study does not reflect the geographic area of diffusion of the considered genotypes, suggesting that area of cultivation and origin may be different. Similarly, no straight association was found between genetic similarity and area of diffusion for those genotypes in a previous study (La Mantia et al., 2005).

Table 2. Leaf size and shape of the 25 Sicilian olive genotypes under trial. For length:area, letters indicate coding ( $\mathrm{H}=$ high, $\mathrm{M}=$-medium, $\mathrm{L}=\mathrm{low}$ ) used for linear discriminant analysis. Means \pm standard errors

\begin{tabular}{cccccc}
\hline Genotype & $\begin{array}{c}\text { Length } \\
(\mathrm{cm})\end{array}$ & $\begin{array}{c}\text { Width } \\
(\mathrm{cm})\end{array}$ & $\begin{array}{c}\text { Area } \\
\left(\mathrm{cm}^{2}\right)\end{array}$ & Length:width & Length:area \\
\hline $\mathrm{BC}$ & $4.85 \pm 0.46$ & $1.11 \pm 0.14$ & $3.93 \pm 0.56$ & $4.36 \pm 0.30$ & $1.23 \pm 0.11(\mathrm{M})$ \\
$\mathrm{BG}$ & $6.20 \pm 0.62$ & $1.33 \pm 0.19$ & $6.40 \pm 0.98$ & $4.66 \pm 0.41$ & $0.97 \pm 0.10(\mathrm{~L})$ \\
$\mathrm{BN}$ & $6.50 \pm 0.65$ & $1.20 \pm 0.16$ & $5.48 \pm 0.83$ & $5.40 \pm 0.42$ & $1.19 \pm 0.12(\mathrm{M})$ \\
$\mathrm{BR}$ & $4.85 \pm 0.59$ & $1.07 \pm 0.14$ & $3.94 \pm 0.89$ & $4.55 \pm 0.37$ & $1.23 \pm 0.11(\mathrm{M})$ \\
$\mathrm{BS}$ & $4.73 \pm 0.51$ & $0.98 \pm 0.12$ & $3.28 \pm 0.61$ & $4.84 \pm 0.31$ & $1.44 \pm 0.14(\mathrm{H})$ \\
$\mathrm{CA}$ & $5.00 \pm 0.60$ & $1.28 \pm 0.17$ & $3.70 \pm 0.78$ & $3.91 \pm 0.33$ & $1.35 \pm 0.13(\mathrm{M})$ \\
$\mathrm{CE}$ & $6.00 \pm 0.78$ & $1.53 \pm 0.26$ & $5.10 \pm 1.11$ & $3.92 \pm 0.52$ & $1.18 \pm 0.14(\mathrm{M})$ \\
$\mathrm{CR}$ & $6.50 \pm 0.85$ & $1.48 \pm 0.21$ & $5.70 \pm 1.21$ & $4.39 \pm 0.55$ & $1.14 \pm 0.13(\mathrm{~L})$ \\
$\mathrm{CV}$ & $5.90 \pm 0.57$ & $1.13 \pm 0.17$ & $4.10 \pm 0.97$ & $5.22 \pm 0.37$ & $1.44 \pm 0.12(\mathrm{H})$ \\
ER & $6.90 \pm 0.83$ & $1.44 \pm 0.19$ & $7.70 \pm 1.18$ & $4.79 \pm 0.51$ & $0.90 \pm 0.11(\mathrm{~L})$ \\
GF & $6.70 \pm 0.81$ & $1.09 \pm 0.20$ & $4.90 \pm 0.81$ & $6.15 \pm 0.49$ & $1.37 \pm 0.13(\mathrm{H})$ \\
LU & $6.60 \pm 0.80$ & $1.42 \pm 0.22$ & $6.10 \pm 0.76$ & $4.65 \pm 0.50$ & $1.08 \pm 0.11(\mathrm{~L})$ \\
MN & $5.14 \pm 0.76$ & $1.39 \pm 0.19$ & $4.46 \pm 0.55$ & $3.70 \pm 0.52$ & $1.15 \pm 0.14(\mathrm{~L})$ \\
MO & $4.77 \pm 0.57$ & $1.10 \pm 0.20$ & $3.72 \pm 0.79$ & $4.32 \pm 0.38$ & $1.28 \pm 0.13(\mathrm{M})$ \\
NE & $6.40 \pm 1.07$ & $1.21 \pm 0.25$ & $5.30 \pm 0.93$ & $5.29 \pm 0.64$ & $1.21 \pm 0.14(\mathrm{M})$ \\
NOB & $6.08 \pm 0.86$ & $1.36 \pm 0.16$ & $6.13 \pm 0.76$ & $4.47 \pm 0.50$ & $1.00 \pm 0.10(\mathrm{~L})$ \\
NOE & $6.16 \pm 0.89$ & $1.19 \pm 0.19$ & $5.37 \pm 0.90$ & $5.17 \pm 0.54$ & $1.15 \pm 0.13(\mathrm{~L})$ \\
NOM & $5.52 \pm 1.06$ & $1.04 \pm 0.22$ & $4.42 \pm 0.87$ & $5.29 \pm 0.62$ & $1.25 \pm 0.13(\mathrm{M})$ \\
OM & $6.30 \pm 0.73$ & $1.42 \pm 0.17$ & $6.00 \pm 1.06$ & $4.44 \pm 0.46$ & $1.05 \pm 0.12(\mathrm{~L})$ \\
PA & $5.47 \pm 0.79$ & $1.04 \pm 0.22$ & $3.90 \pm 0.97$ & $5.25 \pm 0.51$ & $1.40 \pm 0.14(\mathrm{H})$ \\
PC & $5.77 \pm 0.81$ & $0.98 \pm 0.18$ & $4.22 \pm 0.77$ & $5.90 \pm 0.48$ & $1.37 \pm 0.13(\mathrm{H})$ \\
PR & $5.61 \pm 0.74$ & $1.27 \pm 0.17$ & $5.14 \pm 0.78$ & $4.43 \pm 0.45$ & $1.09 \pm 0.11(\mathrm{~L})$ \\
SA & $4.80 \pm 0.52$ & $1.41 \pm 0.23$ & $4.70 \pm 0.65$ & $3.40 \pm 0.38$ & $1.02 \pm 0.10(\mathrm{~L})$ \\
TO & $4.07 \pm 0.86$ & $0.96 \pm 0.17$ & $2.89 \pm 0.59$ & $4.24 \pm 0.51$ & $1.41 \pm 0.13(\mathrm{H})$ \\
VE & $4.35 \pm 0.61$ & $0.87 \pm 0.17$ & $2.79 \pm 0.74$ & $4.99 \pm 0.39$ & $1.56 \pm 0.15(\mathrm{H})$ \\
\hline
\end{tabular}


Table 3. Fruit morphological traits and chemical composition of the 25 Sicilian olive genotypes under trial. Means \pm standard errors

\begin{tabular}{|c|c|c|c|c|c|c|}
\hline Genotype & Width:height & Flesh:pit & $\begin{array}{l}\text { Volume } \\
\left(\mathrm{cm}^{3}\right)\end{array}$ & $\begin{array}{l}\text { Oleic acid } \\
(\%)\end{array}$ & Oleic:linoleic $^{\top}$ & $\begin{array}{l}\text { Polyphenols } \\
\text { (ppm) }\end{array}$ \\
\hline $\mathrm{BC}$ & $0.74 \pm 0.09$ & $2.39 \pm 1.31$ & $3.28 \pm 0.74$ & 69.6 & 6.2 & 133 \\
\hline BG & $0.60 \pm 0.07$ & $1.92 \pm 0.98$ & $1.93 \pm 0.36$ & 68.7 & 10.8 & 492 \\
\hline $\mathrm{BN}$ & $0.67 \pm 0.09$ & $3.09 \pm 1.59$ & $2.82 \pm 0.59$ & 69.6 & 6.2 & 133 \\
\hline $\mathrm{BR}$ & $0.62 \pm 0.08$ & $2.17 \pm 1.19$ & $3.41 \pm 0.71$ & 72.5 & 7.2 & 277 \\
\hline BS & $0.69 \pm 0.09$ & $2.34 \pm 1.27$ & $2.86 \pm 0.57$ & 69.6 & 6.2 & 133 \\
\hline $\mathrm{CA}$ & $0.68 \pm 0.09$ & $3.20 \pm 1.61$ & $3.55 \pm 0.72$ & 80.3 & 19.1 & 366 \\
\hline $\mathrm{CE}$ & $0.77 \pm 0.10$ & $5.22 \pm 2.23$ & $6.66 \pm 1.16$ & 74.9 & 7.3 & 469 \\
\hline $\mathrm{CR}$ & $0.80 \pm 0.10$ & $3.12 \pm 1.48$ & $2.15 \pm 0.44$ & 74.1 & 12.4 & 136 \\
\hline $\mathrm{CV}$ & $0.82 \pm 0.11$ & $4.09 \pm 2.17$ & $4.97 \pm 0.98$ & 67.4 & 8.0 & 278 \\
\hline ER & $0.62 \pm 0.08$ & $2.56 \pm 1.39$ & $2.17 \pm 0.45$ & 71.7 & 8.7 & 454 \\
\hline GF & $0.87 \pm 0.12$ & $7.61 \pm 3.11$ & $15.61 \pm 2.94$ & 69.4 & 6.0 & 126 \\
\hline LU & $0.82 \pm 0.11$ & $5.35 \pm 2.36$ & $7.96 \pm 1.54$ & 67.9 & 6.6 & 221 \\
\hline $\mathrm{MN}$ & $0.78 \pm 0.10$ & $2.00 \pm 1.16$ & $2.68 \pm 0.55$ & 65.0 & 5.3 & 364 \\
\hline MO & $0.72 \pm 0.09$ & $3.32 \pm 1.69$ & $6.57 \pm 1.20$ & 61.4 & 4.1 & 273 \\
\hline $\mathrm{NE}$ & $0.65 \pm 0.08$ & $4.36 \pm 2.24$ & $6.36 \pm 1.09$ & 64.0 & 5.2 & 209 \\
\hline NOB & $0.97 \pm 0.15$ & $7.69 \pm 3.28$ & $9.11 \pm 1.89$ & 73.7 & 9.8 & 261 \\
\hline NOE & $0.81 \pm 0.11$ & $4.48 \pm 2.21$ & $5.02 \pm 0.96$ & 66.4 & 5.4 & 181 \\
\hline NOM & $0.82 \pm 0.11$ & $6.01 \pm 3.05$ & $10.27 \pm 2.04$ & 61.2 & 3.8 & 160 \\
\hline $\mathrm{OM}$ & $0.67 \pm 0.09$ & $3.12 \pm 1.41$ & $4.67 \pm 0.87$ & 71.7 & 12.1 & 123 \\
\hline PA & $0.64 \pm 0.08$ & $3.75 \pm 1.82$ & $6.24 \pm 1.08$ & 78.6 & 21.0 & 214 \\
\hline $\mathrm{PC}$ & $0.79 \pm 0.10$ & $4.87 \pm 2.46$ & $13.10 \pm 2.53$ & 69.4 & 6.0 & 126 \\
\hline PR & $0.71 \pm 0.09$ & $2.00 \pm 1.09$ & $2.22 \pm 0.49$ & 74.9 & 12.9 & 215 \\
\hline SA & $0.63 \pm 0.08$ & $6.57 \pm 3.66$ & $9.78 \pm 1.92$ & 67.1 & 4.5 & 270 \\
\hline $\mathrm{TO}$ & $0.92 \pm 0.14$ & $4.11 \pm 2.13$ & $7.59 \pm 1.46$ & 63.6 & 4.4 & 105 \\
\hline VE & $0.77 \pm 0.10$ & $3.47 \pm 1.69$ & $3.76 \pm 0.71$ & 69.9 & 6.0 & 138 \\
\hline
\end{tabular}

${ }^{1}$ Data from Caruso et al., 2007.

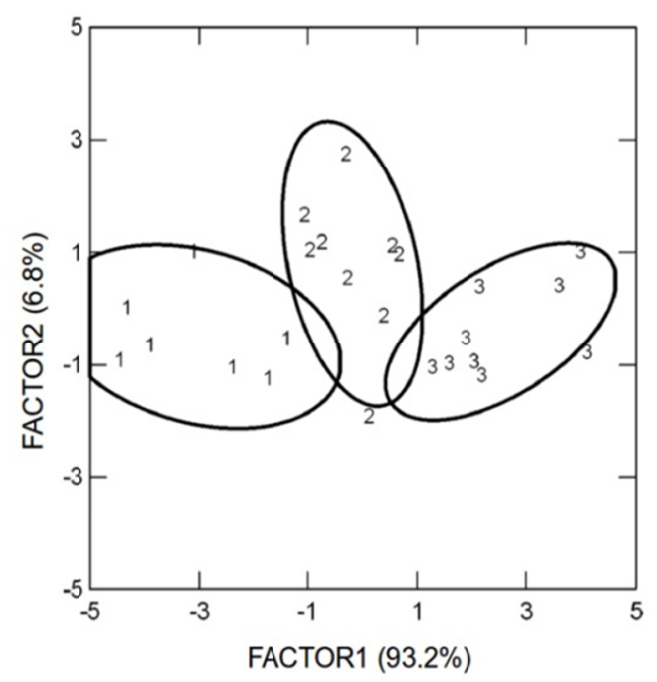

Figure 5. Canonical score plot from linear discriminant analysis for leaf shape, size and carbohydrate contents in the 25 olive genotypes under trial. Genotypes groups from PCA and cluster analysis $(1=$ cluster $1,2=$ cluster 2 , $3=$ cluster 3 ) 
In summary, PCA and cluster analyses indicate that there is a group of seven genotypes which is distinguished for small, elongated leaves along with high mannitol and glucose, while there is another group of nine genotypes which is distinguished for high leaf area. Within a local pool of genotypes, variation in leaf size and shape should be indicative of environmental adaptation with small, elongated leaves being better adapted to dry, high radiation environments (Abrams et al., 1990), and large leaves being indicative of less dry environments and possibly faster growth. In addition, the ability to accumulate mannitol, and in part glucose, in olive leaves may increase tolerance to drought and salinity (Gucci et al., 1998; Xyloiannis et al., 1999), low winter temperatures (Rejšková et al., 2007), or even provide additional protection against oxidative stress (Lo Bianco, Losciale, Manfrini, \& Corelli Grappadelli, 2011). Therefore, genotypes of cluster 1 should be more tolerant to abiotic stress than those of cluster 3 .

When genotypes were grouped by clusters obtained with PCA, LDA was able to fully separate the three groups (Figure 5) with a canonical discriminant function after a backward step analysis that included leaf area, length:width, malic acid, and mannitol. Canonical score plot (Figure 5) and Mahalanobis distances also confirm an intermediate position for cluster 2. The same results were obtained when genotypes were grouped by level (high, medium, low) of length:area. Mannitol and malic acid, along with leaf size and shape, were the most important factors to discriminate the three groups of genotype, presumably by their degree of stress tolerance. It is interesting to notice that general indications of drought tolerance reported by Bartolini et al. (1998) for a few of the genotypes investigated in this study (namely MO, NOE, and PA as drought tolerant and MN, NOB, and $\mathrm{OM}$ as drought sensitive) match our classification by multivariate analysis and leaf traits.

Table 4. Eigenvalues and proportion of total variability among olive genotypes as explained by the seven principal components (PC) using leaf size, shape and carbohydrates

\begin{tabular}{cccc}
\hline PC & Eigenvalues & Variance (\%) & $\begin{array}{c}\text { Cumulative variance } \\
(\%)\end{array}$ \\
\hline 1 & 2.46 & 35.2 & 35.2 \\
2 & 1.46 & 20.8 & 56.0 \\
3 & 1.18 & 16.9 & 72.9 \\
4 & 0.99 & 14.2 & 87.1 \\
5 & 0.58 & 8.3 & 95.4 \\
6 & 0.29 & 4.2 & 99.6 \\
7 & 0.04 & 0.4 & 100.0 \\
\hline
\end{tabular}

As for fruit, when size, shape, carbohydrate levels, chemical composition and genotypes were considered together, PCA showed that about $70 \%$ of the variability observed was explained by the first three components (Table 6). PC1, PC2, and PC3 accounted for 37, 20, and 13\% of the total variability, respectively. Like in leaves, further analysis with perceptual mapping procedures (biplot) and clustering produced some interesting results. In particular, the analysis revealed some expected associations like the one between fruit width:height, flesh:pit and volume or the one between oleic acid percentage and oleic:linoleic, some associations already revealed by simple correlation analysis, like the one between mannitol and sucrose, and some other interesting relationships, like the association between fruit size and glucose or the one between malic acid, oleic acid and polyphenols (Table 7). Many of the observed associations can be related to the growth stage of our fruits. Our olives were collected green at the pre-veraison stage, toward the end of mesocarp development. At this stage, glucose is still a major component (Marsilio et al., 2001) and may represent the primary driving force for cell turgor and expansion. It is therefore not surprising its association with fruit size, even across genotypes. Furthermore, at the green stage, the olive fruit is making some photosynthesis, basically re-fixing the $\mathrm{CO}_{2}$ derived from mitochondrial respiration of photoassimilates through the CAM and C4 photosynthetic pathways (Sánchez, 1994). The formation of malic acid and pyruvate along this pathway together with the role of pyruvate as substrate for lipid and oil formation can explain the observed association between malic and oleic acid; more complex and less immediate is the link between malic acid and polyphenols, synthesized from phosphoenolpyruvate through the shikimic acid pathway (Conde et al., 2008). 
In addition to multiple associations among fruit traits and carbohydrates, cluster analysis on standardized component scores allowed for the individuation of three main groups associating specific fruit parameters with certain genotypes. In particular, cluster analysis indicated that BG, BR, CR, ER, GF, LU, NOB, NOE, NOM, $\mathrm{OM}, \mathrm{PR}, \mathrm{PC}$, and SA form one group along with fruit width:height, flesh:pit, volume, and glucose; CA, CE, MO, PA, TO, and VE form a second group along with malic acid, oleic acid, oleic:linoleic, and polyphenols; BC, BN, $\mathrm{BS}, \mathrm{CV}, \mathrm{MN}$, and NE form a third group along with fruit mannitol and sucrose (Table 7). According to this clustering profile, genotypes belonging to cluster 1 with larger fruits rich in glucose may be more suited to double processing, olive oil or table olives; indeed, some of those genotypes (BR, GF, LU, NOB, NOE, NOM, $\mathrm{PC}$ and in part SA) are currently used for oil and/or table olives; those of cluster 2, rich in oleic acid and polyphenols, should produce best quality and more stable olive oil. Despite their association with mannitol, genotypes of cluster 3 are reported as low to medium oil yielding (Caruso et al., 2007). This seems to disagree with previous findings showing a relationship between mannitol and oil content in olives (Marsilio et al., 2001).

Table 5. Standardized component coordinates for olive genotypes, leaf size, shape and carbohydrates from biplot analysis and grouping by cluster analysis

\begin{tabular}{|c|c|c|c|c|}
\hline & $\mathrm{PC} 1$ & $\mathrm{PC} 2$ & PC3 & Cluster \\
\hline BC & 0.846 & -0.903 & 0.456 & 1 \\
\hline BS & 2.890 & -1.323 & 0.338 & 1 \\
\hline MO & 1.494 & -0.628 & 0.121 & 1 \\
\hline PA & 2.939 & 0.263 & 0.397 & 1 \\
\hline $\mathrm{PC}$ & 2.751 & 1.821 & 0.724 & 1 \\
\hline VE & 2.732 & -0.176 & -0.548 & 1 \\
\hline NOE & 1.013 & 1.179 & 1.436 & 1 \\
\hline Glucose & 2.286 & -1.941 & 1.635 & 1 \\
\hline Mannitol & 3.390 & 1.915 & 1.416 & 1 \\
\hline Sucrose & 2.307 & 1.866 & 2.248 & 1 \\
\hline Length:width & 2.139 & 3.699 & -0.907 & 1 \\
\hline Length:area & 4.165 & -0.652 & -2.275 & 1 \\
\hline $\mathrm{BN}$ & -0.509 & 1.387 & -0.688 & 2 \\
\hline $\mathrm{BR}$ & 0.006 & -0.837 & -0.226 & 2 \\
\hline $\mathrm{CA}$ & 0.132 & -1.575 & -0.160 & 2 \\
\hline $\mathrm{CV}$ & 0.628 & 0.915 & -2.180 & 2 \\
\hline $\mathrm{CR}$ & 0.285 & 0.391 & 1.366 & 2 \\
\hline GF & 0.269 & 1.132 & -1.273 & 2 \\
\hline $\mathrm{NE}$ & -0.374 & 0.563 & -0.065 & 2 \\
\hline NOM & 0.822 & 0.033 & -0.02 & 2 \\
\hline TO & 0.358 & -0.975 & -1.566 & 2 \\
\hline Malic acid & -1.279 & 1.955 & -3.122 & 2 \\
\hline BG & -1.269 & 1.144 & 0.536 & 3 \\
\hline $\mathrm{CE}$ & -1.084 & -0.412 & -0.232 & 3 \\
\hline ER & -3.157 & 1.409 & 0.503 & 3 \\
\hline $\mathrm{LU}$ & -1.431 & 0.274 & 0.240 & 3 \\
\hline $\mathrm{MN}$ & -1.690 & -1.158 & -0.052 & 3 \\
\hline NOB & -2.819 & 0.478 & -0.435 & 3 \\
\hline $\mathrm{OM}$ & -1.660 & -0.885 & 0.628 & 3 \\
\hline PR & -1.701 & -0.614 & -0.082 & 3 \\
\hline SA & -1.472 & -1.50 & 0.787 & 3 \\
\hline Leaf area & -3.668 & 2.470 & 1.718 & 3 \\
\hline
\end{tabular}


Table 6. Eigenvalues and proportion of total variability among olive genotypes as explained by the seven principal components (PC) using fruit carbohydrates, chemical composition, and morphological traits

\begin{tabular}{cccc}
\hline PC & Eigenvalues & Variance (\%) & Cumulative variance (\%) \\
\hline 1 & 3.72 & 37.2 & 37.2 \\
2 & 1.96 & 19.6 & 56.8 \\
3 & 1.28 & 12.8 & 69.6 \\
4 & 0.98 & 9.8 & 79.4 \\
5 & 0.66 & 6.6 & 86.0 \\
6 & 0.51 & 5.1 & 91.1 \\
7 & 0.40 & 4.0 & 95.1 \\
8 & 0.29 & 2.9 & 98.0 \\
9 & 0.14 & 1.4 & 99.4 \\
10 & 0.06 & 0.6 & 100.0 \\
\hline
\end{tabular}

Table 7. Standardized component coordinates for olive genotypes, fruit carbohydrates, chemical composition, and morphological traits from biplot analysis and grouping by cluster analysis

\begin{tabular}{|c|c|c|c|c|}
\hline & PC1 & PC2 & PC3 & Cluster \\
\hline BG & 3.335 & 0.318 & 0.152 & 1 \\
\hline BR & 1.166 & -0.062 & -0.524 & 1 \\
\hline CR & 0.965 & -0.470 & -0.398 & 1 \\
\hline ER & 2.500 & -0.137 & 0.107 & 1 \\
\hline GF & -3.863 & -0.268 & 0.684 & 1 \\
\hline LU & -2.271 & -0.589 & -0.319 & 1 \\
\hline NOB & -2.523 & -0.769 & 0.900 & 1 \\
\hline NOM & -3.221 & 0.409 & -0.228 & 1 \\
\hline $\mathrm{OM}$ & 0.757 & -0.593 & -0.313 & 1 \\
\hline PR & 0.543 & -1.294 & -0.865 & 1 \\
\hline $\mathrm{PC}$ & -1.171 & 0.779 & 0.574 & 1 \\
\hline SA & -0.351 & 0.654 & 0.925 & 1 \\
\hline NOE & -0.927 & 0.249 & -0.052 & 1 \\
\hline Glucose & 3.625 & 0.941 & 0.841 & 1 \\
\hline Width:height & -3.599 & 0.352 & 0.953 & 1 \\
\hline Flesh:pit & -3.711 & -0.031 & 2.761 & 1 \\
\hline Volume & -3.767 & 0.549 & 2.325 & 1 \\
\hline CA & 2.364 & -1.986 & 0.965 & 2 \\
\hline $\mathrm{CE}$ & 0.536 & -0.195 & 0.917 & 2 \\
\hline MO & -0.522 & 0.917 & -0.399 & 2 \\
\hline PA & 0.610 & -2.272 & 0.073 & 2 \\
\hline TO & -2.068 & 0.728 & -0.297 & 2 \\
\hline VE & -0.563 & -0.008 & -0.601 & 2 \\
\hline Malic acid & 2.512 & 1.003 & 3.236 & 2 \\
\hline Oleic acid & 1.935 & -3.720 & 1.183 & 2 \\
\hline Oleic:linoleic & 2.091 & -3.976 & 0.769 & 2 \\
\hline Polyphenols & 2.376 & -0.813 & 1.692 & 2 \\
\hline $\mathrm{BC}$ & 2.497 & 1.932 & 0.438 & 3 \\
\hline $\mathrm{BN}$ & -0.359 & -0.268 & -1.097 & 3 \\
\hline BS & 0.927 & 0.607 & -0.781 & 3 \\
\hline $\mathrm{CV}$ & 0.727 & 0.681 & 0.850 & 3 \\
\hline $\mathrm{MN}$ & -0.105 & 0.123 & -0.616 & 3 \\
\hline NE & 1.015 & 1.515 & -0.096 & 3 \\
\hline Mannitol & 2.575 & 2.587 & 0.627 & 3 \\
\hline Sucrose & 2.910 & 2.774 & 0.593 & 3 \\
\hline
\end{tabular}


In addition, LDA on groups of genotypes obtained from PCA or classified by oil yield did not reveal any significant discriminatory function (data not shown). Oil content was not directly measured in our samples, and a direct association between mannitol and oil formation cannot be ruled out. Nevertheless, our results (simple correlation, PCA or LDA) do not show any implication of fruit mannitol in fruit growth or chemical composition.

Overall, MO, PA, and VE may represent more suitable options for olive growing and olive oil production in areas where unfavorable environmental conditions are frequent or more severe. Those genotypes should in fact combine a good degree of drought and abiotic stress tolerance with high quality and stable olive oils. On the other hand, genotypes like CE may require greater cultural cares to avoid drought or other stressful conditions and ultimately express their productive (oil yield) and quality potential.

\section{References}

Abebe, T., Guenzi, A. C., Martin, B., \& Cushman, J. C. (2003). Tolerance of mannitol-accumulating transgenic wheat to water stress and salinity. Plant Physiology, 131, 1748-1755. http://dx.doi.org/10.1104/pp.102.003616

Abrams, M. D., Kubiske, M. E., \& Steiner, K. C. (1990). Drought adaptations and responses in five genotypes of Fraxinus pennsyhanica Marsh.: photosynthesis, water relations and leaf morphology. Tree Physiology, 6, 305-315. http://dx.doi.org/10.1093/treephys/6.3.305

Barker, S. A. (1955). Acyclic sugar alcohols. In K. Paech \& M. V. Tracey (Eds.), Modern Methods of Plant Analysis (pp. 55-63). Berlin, Germany: Springer-Verlag.

Bartolini, G., Prevost, G., Messeri, C., \& Carignani, G. (1998). Olive germplasm: cultivars and world-wide collections. Seed and Plant Genetic Resources Service, FAO, Rome.

Bieleski, R. L. (1982). Sugar alcohols. In F. A. Loewus, \& W. Tanner (Eds.), Plant Carbohydrates. I. Intracellular Carbohydrates (pp. 158-192). Berlin, Germany: Springer-Verlag.

Caruso, T., Caltabellotta, D., \& Motisi, A. (2007). CULTIVAR DI OLIVO SICILIANE: Identificazione, validazione, caratterizzazione morfologica e molecolare e qualità degli oli. Palermo, Italy: Dipartimento Colture Arboree (University of Palermo) and Assessorato Agricoltura e Foreste, Regione Siciliana.

Cataldi, T. R. I., Margiotta, G., Iasi, L., Di Chio, B., Xiloyannis, C., \& Bufo, S. A. (2000). Determination of sugar compounds in olive plant extracts by anion-exchange chromatography with pulsed amperometric detection. Analytical Chemistry, 72, 3902-3907. http://dx.doi.org/10.1021/ac000266o

Conde, C., Delrot, S., \& Gerós, H. (2008). Physiological, biochemical and molecular changes occurring during olive development and ripening. Journal of Plant Physiology, 165, 1545-1562. http://dx.doi.org/10.1016/j.jplph.2008.04.018

Conde, C., Silva, P., Agasse, A., Lemoine, R., Delrot, S., Tavares, R., \& Gerós, H. (2007). Utilization and transport of mannitol in Olea europaea and implications on salt stress tolerance. Plant \& Cell Physiology, 48, 42-53. http://dx.doi.org/10.1093/pcp/pcl035

Connor, D. J., \& Fereres, E. (2005). The physiology of adaptation and yield expression in olive. Horticultural Reviews, 31, 155-229. http://dx.doi.org/10.1002/9780470650882.ch4

Dichio, B., Xiloyannis, C., Angelopoulos, K., Nuzzo, V., Bufo, S. A., \& Celano, G. (2003). Drought-induced variations of water relations parameters in Olea europaea. Plant and Soil, 257, 381-389. http://dx.doi.org/10.1023/A:1027392831483

Favia, F., \& Celano, G. (2004). I sistemi olivicoli in terreni collinari e montani: Basilicata e Campania. Proceedings of the meeting Il futuro dei sistemi olivicoli in aree marginali: aspetti socio-economici, conservazione delle risorse naturali e produzioni di qualità (pp. 123-158). Potenza, Italy: L'Aquilone.

Flora, L. F., \& Madore, M. A. (1993). Stachyose and mannitol transport in olive (Olea europaea L.). Planta, 189, 484-490. http://dx.doi.org/10.1007/BF00198210

Galinski, E. A. (1993). Compatible solutes of halophilic eubacteria: Molecular principles, water-solute interaction, stress protection. Experientia, 49, 487-496. http://dx.doi.org/10.1007/BF01955150

Gucci, R., Moing, A., Gravano, E., \& Gaudillére, J. P. (1998). Partitioning of photosynthetic carbohydrates in leaves of salt-stressed olive plants. Australian Journal of Plant Physiology, 25, 571-579. http://dx.doi.org/10.1071/PP98003 
Karakas, B., Ozias-Akins, P., Stushnoff, C., Suefferheld, M., \& Rieger, M. (1997). Salinity and drought tolerance of mannitol-accumulating transgenic tobacco. Plant, Cell \& Environment, 20, 609-616. http://dx.doi.org/10.1111/j.1365-3040.1997.00132.x

La Mantia, M., Lain, O., Caruso, T., \& Testolin, R. (2005). SSR-based DNA fingerprints reveal the genetic diversity of Sicilian olive (Olea europaea L.) germplasm. Journal of Horticultural Science and Biotechnology, 80, 628-632.

Lo Bianco, R., Losciale, P., Manfrini, L., \& Corelli Grappadelli, L. (2011). Possible role of mannitol as an oxygen radical scavenger in olive. Acta Horticulturae, 924, 83-88.

Lo Bianco, R., Rieger, M., \& Sung, S. S. (2000). Effect of drought on sorbitol and sucrose metabolism in sinks and $\begin{array}{llllll}\text { sources } & \text { of } & \text { peach. } & \text { Physiologia } & \text { Plantarum, } & \text { 108, }\end{array}$ http://dx.doi.org/10.1034/j.1399-3054.2000.108001071.x

Macaluso, L., Lo Bianco, R., \& Rieger, M. (2007). Mannitol-producing tobacco exposed to varying levels of water, light, temperature and paraquat. Journal of Horticultural Science and Biotechnology, 82, 979-985.

Marsilio, V., Campestre, C., Lanza, B., \& De Angelis, M. (2001). Sugar and polyol compositions of some European olive fruit varieties (Olea europaea L) suitable for table olive purposes. Food Chemistry, 72, 485-490. http://dx.doi.org/http://dx.doi.org/10.1016/S0308-8146(00)00268-5

Moriana, A., Orgaz, F., Pastor, M., \& Fereres, E. (2003). Yield responses of mature olive orchard to water deficits. Journal of the American Society for Horticultural Science, 123, 425-431.

Noiraud, N., Maurousset, L., \& Lemoine, R. (2001). Transport of polyols in higher plants. Plant Physiology and Biochemistry, 39, 717-728. http://dx.doi.org/http://dx.doi.org/10.1016/S0981-9428(01)01292-X

Pharr, D. M., Stoop, J. M. H., Williamson, J. D., Studer Feusi, M. E., Massel, M. O., \& Conkling, M. A. (1995). The dual role of mannitol as osmoprotectant and photoassimilate in celery. HortScience, 30, 1182-1188.

Ranney, T. G., Bassuk, N. L., \& Whitlow, T. H. (1991). Osmotic adjustment and solute constituents in leaves and roots of water-stressed cherry (Prunus) trees. Journal of the American Society for Horticultural Science, 116 , 684-688.

Rejšková, A., Patková, L., Stodůlková, E., \& Lipavská, H. (2007). The effect of abiotic stresses on carbohydrate status of olive shoots (Olea europaea L) under in vitro conditions. Journal of Plant Physiology, 164, 174-184. http://dx.doi.org/10.1016/j.jplph.2005.09.011

Rotondi, A, Bendini, A, Cerretani, L, Mari, M, Lecker, G, Toschi, T. G. (2004). Effect of olive ripening degree on the oxidative stability and organoleptic proprieties of Cv Nostrana di Brisighella extra virgin olive oil. Journal of Agriculture and Food Chemistry, 52, 3649-54. http://dx.doi.org/10.1021/jf049845a

Sánchez, J. (1994). Lipid photosynthesis in olive fruit. Progress in Lipid Research, 33, 97-104.

Schulze, E. D., Robichaux, R. H., Grace, J., Rundel, P. W., \& Ehleringer, J. R. (1987). Plant water balance. BioScience, 37, 30-37.

Shen, B., Jensen, R. G., \& Bohnert, H. J. (1997). Mannitol protects against oxidation by hydroxyl radicals. Plant Physiology, 115, 527-532. http://dx.doi.org/10.1104/pp.115.2.527

Smirnoff, N., \& Cumbes, Q. J. (1989). Hydroxyl radical scavenging activity of compatible solutes. Phytochemistry, 28, 1057-1060. http://dx.doi.org/10.1016/0031-9422(89)80182-7

Stoop, J. M. H., Williamson, J. D., \& Pharr, D. M. (1996). Mannitol metabolism in plants: a method for coping with stress. Trends in Plant Science, 1, 139-144. http://dx.doi.org/10.1016/S1360-1385(96)80048-3

Tarczynski, M. C., Jensen, R. G., \& Bohnert, H. J. (1993). Salt protection of transgenic tobacco by production of the osmolyte mannitol. Science, 259, 508-510. http://dx.doi.org/10.1126/science.259.5094.508

Tattini, M., Gucci, R., Romani, A., Baidi, A., \& Everard, J. D. (1996). Changes in non-structural carbohydrates in olive (Olea europaea) leaves during root zone salinity stress. Physiologia Plantarum, 98, 117-124. http://dx.doi.org/10.1111/j.1399-3054.1996.tb00682.x

Wang, Z., \& Stutte, G. W. (1992). The role of carbohydrates in active osmotic adjustment in apple under water stress. Journal of the American Society for Horticultural Science, 117, 816-823.

Xiloyannis, C., Dichio, B., Nuzzo, V., \& Celano, G. (1999). Defense strategies of olive against water stress. Acta Horticulturae, 474, 423-426. 
Zimmermann, M. H., \& Ziegler, H. (1975). List of sugars and sugar alcohols in sieve-tube exudates. In M. H. Zimmerman, \& J. A. Milburn (Eds.), Transport in Plants. 1. Phloem Transport (pp. 480-503). Berlin, Germany: Springer-Verlag.

\section{Copyrights}

Copyright for this article is retained by the author(s), with first publication rights granted to the journal.

This is an open-access article distributed under the terms and conditions of the Creative Commons Attribution license (http://creativecommons.org/licenses/by/3.0/). 